\title{
Prevalence of Undernutrition and Its Associated Factors among Children below Five Years of Age in Bure Town, West Gojjam Zone, Amhara National Regional State, Northwest Ethiopia
}

\author{
Desalegne Amare, ${ }^{1}$ Ayenew Negesse,, Baye Tsegaye, ${ }^{3}$ \\ Birtukan Assefa, ${ }^{4}$ and Birehanu Ayenie ${ }^{5}$ \\ ${ }^{1}$ Department of Nursing, College of Medicine and Health Sciences, Bahir Dar University, P.O. Box 79, Bahir Dar, Ethiopia \\ ${ }^{2}$ Department of Public Health, College of Medicine and Health Sciences, Debre Markos University, Debre Markos, Ethiopia \\ ${ }^{3}$ National Blood Bank, Addis Ababa, Ethiopia \\ ${ }^{4}$ Department of Nursing, College of Medicine and Health Sciences, Debre Markos University, Debre Markos, Ethiopia \\ ${ }^{5}$ Felege Hiwot Referral Hospital, Bahir Dar, Ethiopia
}

Correspondence should be addressed to Desalegne Amare; desa2001@yahoo.com

Received 12 May 2016; Accepted 6 July 2016

Academic Editor: Julio Diaz

Copyright (C) 2016 Desalegne Amare et al. This is an open access article distributed under the Creative Commons Attribution License, which permits unrestricted use, distribution, and reproduction in any medium, provided the original work is properly cited.

Background. Malnutrition is the major public health problem over the world. Developing countries are highly affected. Asian and Sub-Saharan African countries, including Ethiopia, contribute the highest of all. The main aim of this study was to assess the prevalence of undernutrition and its associated factors among children below five years of age. Methods. Community-based cross-sectional survey was conducted on 342 study participants. Simple random sampling technique was used to select sampling kebeles and study units. Weight and height were measured using calibrated instruments. The data were entered into EpiData version 3.1 software and calculated using SPSS version 20.0 statistical software and/or World Health Organization Anthro software with aid of Stat/Transfer. Results. Overall prevalence of undernutrition was 35.5\%, of which 85 (24.9\%), 38 (11.1\%), and 49 (14.3\%) were stunting, wasting, and underweight, respectively. Male children were more affected in both severe and moderate nutritional problems compared to female children. The finding showed that $27(7.9 \%)$ had severe stunting, $15(4.4 \%)$ had severe wasting, and $11(3.2 \%)$ had severe underweight, respectively. Conclusion. Undernutrition was high in Bure town among children below five years of age. Male sex, maternal educational status, low household income, preterm babies, absence of antenatal follow-up, diarrhea, and respiratory infections within one-month duration were factors affecting undernutrition.

\section{Background}

Malnutrition is one of the major public health problems all over the world. Currently, it faces and associated with more than $41 \%$ of the deaths that occur annually in children from 6 to 24 months of age in developing countries, which were approximately 2.3 million [1].

Worldwide, 165 million children below five years of age were affected with undernutrition, of which $26 \%$ were stunted. This figure reduced by 35\% from 253 million in 1990. The prevalence of stunting was $36 \%$ in Africa and $27 \%$ in Asia. These remain a public health problem, one that often goes unrecognized. More than $90 \%$ of stunted children in the world have been living in Africa and Asia. An estimated $80 \%$ of world's stunted children lived in just fourteen countries (India, Nigeria, China, Pakistan, Indonesia, Bangladesh, Ethiopia, Democratic Republic of Congo, Philippines, United Republic of Tanzania, Egypt, Kenya, Uganda, and Sudan). Sub-Saharan Africa and South Asia were the home to threefourths of the world's stunted children, $40 \%$ and $39 \%$, respectively [2-4].

Globally, an estimated 101 million children below five years of age were underweight. These accounted for $16 \%$ of children below five years of age. The prevalence was the 
highest, which was 33\%, followed by Sub-Saharan Africa, which was $21 \%$. These were 59 million in South Asia, while 30 million were in sub-Saharan Africa [4]. Globally, the prevalence has declined, from $25 \%$ in 1990 to $16 \%$ in 2013 ; these reduced by $37 \%$ [3].

The other predictor of undernutrition is wasting. Globally, 52 million children below five years of age were moderately or severely wasted, $11 \%$ decrease from 58 million in 1990. More than 29 million children below five years of age, an estimated 5\%, suffered from severe wasting [4].

Wasting was decreased by $36 \%$ from 1990, which was 159 million, while 51 million children below five years of age were wasted, and 17 million were severely wasted in 2013. The prevalence in 2013 was $8 \%$ and closely a third of that was for severe wasting, totaling 3\% and approximately twothirds of all wasted children who lived in Asia and one-third in Africa [3]. The prevalence of wasting was the highest in South Asia, which was approximately $16 \%$. This moderate or severe wasting was the highest in India, which had more than 25 million wasted children [3].

About one-third of deaths among children below five years of age were attributed to undernutrition and it can lead children to be at greater risk of death and severe illness due to common childhood infections, such as pneumonia, diarrhea, malaria, human immunodeficiency virus, or AIDS and measles [3]. World Health Organization (WHO) in 2001 reported that $54 \%$ of all childhood mortality was attributable, directly or indirectly, to malnutrition [5].

It is not only an important cause of mortality and morbidity but also leads to physical and mental impairment in children. Health and physical consequences of prolonged states of malnourishment among children were delay in their physical growth, lower intellectual quotient, poor cognitive ability, decreased economic productivity, decreased reproductive performance, poor school achievement and poor school performance, greater behavioral problems and deficient social skills, and susceptibility to contracting diseases [6-14].

In Ethiopia, the levels of undernutrition were not decreased significantly. The 2011 EDHS report showed that stunting was $58 \%$ in $2000,51 \%$ in 2005 , and $44 \%$ in 2011 . This report also showed that wasting was $12 \%$ from 2000 to 2005 and $10 \%$ in 2011 . The third predictor is underweight, which was $41 \%$ in $2000,33 \%$ in 2005 , and $29 \%$ in 2011 [15]. The national trend showed that stunting and underweight prevalence continued to decrease but at a slow pace. The above trend showed that prevalence of wasting was not declined for three consecutive surveys. Therefore, the main aim of this study was to assess the prevalence of undernutrition and its associated factors among children below five years of age in Bure town.

\section{Methods}

2.1. Setting. This study was conducted in Bure town, which is found at $411 \mathrm{~km}$ far from the capital of Ethiopia, Addis Ababa, and about $148 \mathrm{~km}$ from the capital of Amhara regional state, Bahir Dar. Geographically, it is found that, 700-2750 meters above sea level, average rainfall is $1750 \mathrm{~mL}$ and the temperature variation ranges from 17 to 27 degree centigrade. The town has eight Kebeles and total population of 52,164, out of which 25,169 were males and 26,995 were females.

2.2. Design. A community-based cross-sectional study design was conducted from April 24 to May 12, 2015.

2.3. Population. All children below five years of age in the town were the source population and those children below five years of age who lived in selected kebeles were the study population. All houses selected by lottery method were sampled houses and children below five years of age who lived in these houses were the study unit.

2.4. Sample Size and Sampling Techniques. To determine the sample size, single population proportion formula was used. The sample size of the study was determined into the consideration of $95 \%$ confidence interval, $5 \%$ margin of error, and $28.2 \%$ prevalence of undernutrition from previous study in Gumbrit [16]. After including 10\% nonresponse rates, 342 individuals were included in the study. From all kebeles of Bure, two of them were selected using simple random sampling technique. Households and study units were also selected using simple random sampling method. All children below five years of age were included in the study.

2.5. Variables. Sociodemographic characteristics (family income, maternal education, paternal education, maternal occupation, paternal occupation, religion, family size, and maternal age) and child characteristics (child sex, child age, low birth weight, and gestational age) were independent variables. Stunting, wasting, and underweight were the dependent variables.

2.6. Data Collection Tool. Data were collected using a structured questionnaire. The questionnaire was prepared in English language, and then it was translated into a local language, Amharic, by language experts. Comparison was made on the consistency of the two versions.

2.7. Measurements. Anthropometric measurements (weight and height) were done according to WHO standard manual [17]. A portable stadiometer was used to measure older children (above two years) and calibrated length board was used for younger children (less than two years). Older children were measured at standing position, while younger children less than two years were measured at lie down position. The child was measured without shoes, hats, and hair ornaments. During measurement their head, shoulders, buttocks, and heels were attached with the vertical surface of the stadiometer. The height measurement was recorded to the nearest $0.1 \mathrm{~cm}$.

Weight was measured using infant and toddler weighting scales. The scale was zeroed for each measurement. Each child was measured with bare foot and light clothing. Infants were measured in supine position and older children were measured in sitting position. Weight was recorded immediately after measurement to the nearest $0.1 \mathrm{~kg}$. Underweight, 
wasting, and stunting were computed using weight and height measurement.

\section{Standard Definition}

Underweight is weight for age, stunting is height for age, and wasting is weight for height, which are $<-2$ SD of the WHO Growth Standard chart [18].

3.1. Data Quality Control. Pretest was done out of sampling kebeles. Necessary information and correction were made on the clarity of language and workability of the questionnaire. The questionnaire was modified based on the pretest findings. Training was provided for data collectors and supervisors on the purpose of the study, procedure, and techniques of interview. Training was provided for data collectors on how to position and measure the child and calibrate the instruments. Investigators made close monitoring and supportive supervision throughout the data collection period.

3.2. Analysis. Data were entered into EpiData version 3.1 and transferred into SPSS version 20.0 software for further analysis. Thereafter, the data were imported to WHO Anthro software with the aid of Stat/Transfer software to compute individual level nutritional survey. Data were checked for its' completeness and consistency. Data were analyzed using binary logistic regression analysis. Statistical associations were checked by $95 \% \mathrm{CI}$ and odds ratio. Those variables which had $p$ value less than 0.2 in binary logistical regression analysis were eligible for multiple logistic regressions. Finally, adjusted odds ratio was checked and the significant variables were considered as associated factors for undernutrition. The data were presented using tables, graphs, and text.

3.3. Ethics. Ethical approval was obtained from Debre Markos University Medicine and Health Science College's ethical review committee. Verbal consent was obtained from each parent. We assured that the information obtained from them was maintained.

\section{Results}

4.1. Sociodemographic Characteristics. Three hundred fortytwo study participants were included in the study. The response rate was $100 \%$. Among all participants, 174 (50.9\%) and $168(49.1 \%)$ were females and males, respectively. The mean age of the children and mothers was $28.94 \pm 16.418$ months and $28.48 \pm 6.2$ years, respectively. Most, 319 (93.3\%) of the caretakers and/or mothers, were orthodox Christians.

Of the total parents, 107 (31.3\%) and 37 (10.7\%) could not read and write, respectively. Majority, 205 (59.9\%) of mothers, were housewives. Out of 342 participants, 143 (41.8\%) had monthly income of less than 750 birr (Table 1).

4.2. Undernutrition. The overall prevalence of undernutrition among children below five years of age was $35.5 \%$, of

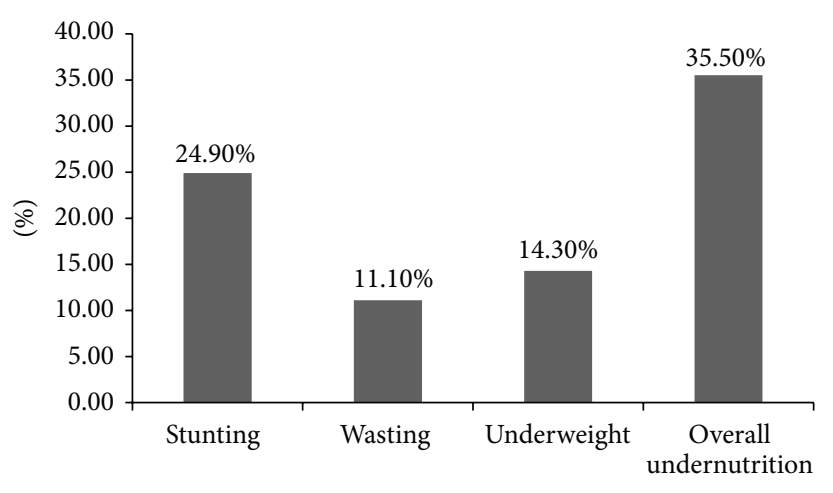

FIGURE 1: Magnitude of undernutrition among children below five years of age.

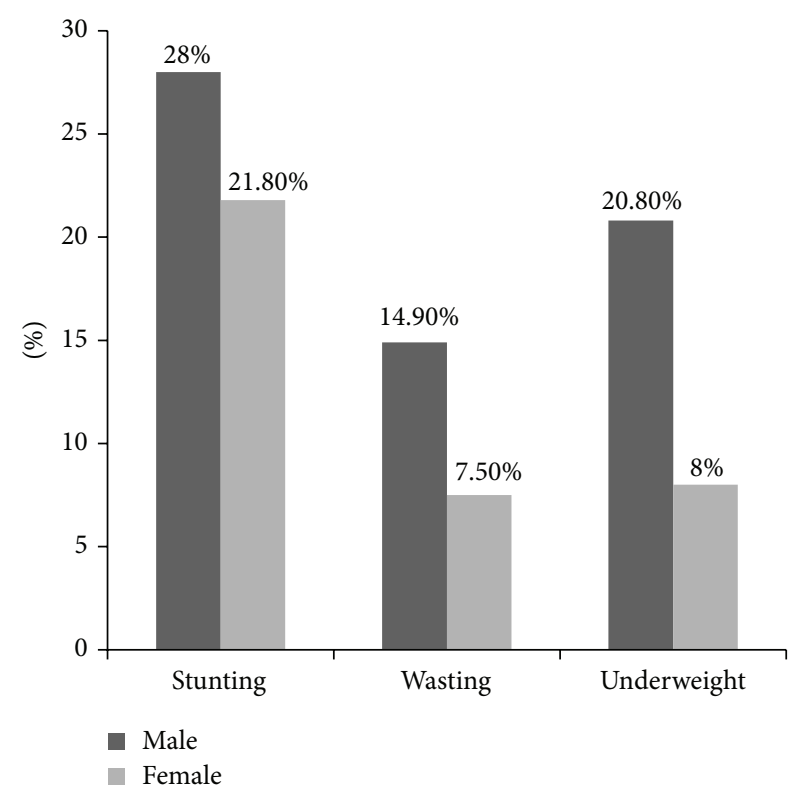

Figure 2: Prevalence of undernutrition regarding gender.

which 85 (24.9\%), 38 (11.1\%), and 49 (14.3\%) were stunted, wasted, and underweight, respectively (Figure 1). Table 2 showed that $27(7.9 \%), 15(4.4 \%)$, and $11(3.2 \%)$ children had severe stunting, wasting, and undernutrition, respectively (Table 2).

About $28 \%, 14.9 \%$, and $20.8 \%$ of males were stunting, wasting, and underweight, correspondingly (Figure 2). Of those male children, $27(10.7 \%), 12(7.1 \%)$, and $10(6 \%)$ were severely stunted, wasted, and underweight, respectively (Table 3).

In the age range of $12-23,24(32.9 \%)$ were stunted, and from 36 to 47 months, 18 (29.5\%) and 13 (21.3\%) were stunted and underweight, respectively (Table 4).

\section{Risk Factors}

In multiple logistic regression analysis, paternal educational status, diarrheal disease occurrence, and respiratory tract 
TABLE 1: Socioeconomic and demographic variables of respondents in Bure town, West Gojjam Zone, northwest Ethiopia, in 2015.

\begin{tabular}{|c|c|c|c|}
\hline Variables & & Frequency & Percent \\
\hline \multirow{2}{*}{ Sex } & Male & 168 & 49.1 \\
\hline & Female & 174 & 50.9 \\
\hline \multirow{5}{*}{ Age } & $<12$ months & 57 & 17.3 \\
\hline & $12-23$ months & 73 & 21.3 \\
\hline & 24-35 months & 78 & 22.8 \\
\hline & 36-47 months & 61 & 18.8 \\
\hline & $48-59$ months & 71 & 20.8 \\
\hline \multirow{2}{*}{ Religion } & Orthodox & 319 & 93.3 \\
\hline & Others & 23 & 5.6 \\
\hline \multirow{5}{*}{ Maternal educational status } & Cannot read and write & 107 & 31.3 \\
\hline & Can read and write & 55 & 16.1 \\
\hline & Primary & 64 & 18.7 \\
\hline & Secondary & 77 & 22.5 \\
\hline & Tertiary & 39 & 11.4 \\
\hline \multirow{5}{*}{ Paternal educational status } & Cannot read and write & 53 & 15.5 \\
\hline & Can read and write & 89 & 26 \\
\hline & Primary & 58 & 17 \\
\hline & Secondary & 80 & 23.4 \\
\hline & Tertiary & 62 & 18.1 \\
\hline \multirow{3}{*}{ Monthly income } & $<750$ & 143 & 41.8 \\
\hline & $750-1500$ & 76 & 22.2 \\
\hline & $>1500$ & 123 & 36 \\
\hline \multirow{4}{*}{ Maternal occupational status } & Housewife & 205 & 59.9 \\
\hline & Government employee & 44 & 12.9 \\
\hline & Private & 31 & 9.1 \\
\hline & Others & 62 & 18.1 \\
\hline \multirow{2}{*}{ Diarrhea in the last one month } & Yes & 42 & 12.3 \\
\hline & No & 300 & 87.7 \\
\hline \multirow{2}{*}{ Respiratory tract infection in the last one month } & Yes & 46 & 13.5 \\
\hline & No & 296 & 86.5 \\
\hline
\end{tabular}

TABLE 2: Severity of undernutrition among children below five years of age.

\begin{tabular}{lccc}
\hline \multicolumn{2}{c}{ Level of malnutrition } & $N$ & $\%$ \\
\hline \multirow{2}{*}{ Stunting } & Severe stunting & 27 & 7.9 \\
& Moderate stunting & 58 & 17 \\
\hline \multirow{2}{*}{ Wasting } & Severe wasting & 15 & 4.4 \\
& Moderate wasting & 23 & 6.7 \\
\multirow{2}{*}{ Underweight } & Severe underweight & 11 & 3.2 \\
& Moderate & 38 & 11.1 \\
\hline
\end{tabular}

infection in the last one month were statistically significant variables for stunting. Those illiterate fathers $(\mathrm{AOR}=5.38$, 95\% CI: 2.07-13.98) and fathers who could only read and write $(\mathrm{AOR}=2.73,95 \% \mathrm{CI}: 1.11-6.72)$ were significantly associated with stunting.

Diarrheal disease (AOR: 2.621, 95\% CI: 1.31-5.25) and acute respiratory tract infection in the last one month (AOR $=2.658$, 95\% CI: 1.34-5.28) were factors independently associated with stunting.
TABLE 3: Nutritional status of under five children by sex.

\begin{tabular}{lcccccc}
\hline \multirow{2}{*}{ Variables } & \multicolumn{2}{c}{ Stunting } & \multicolumn{2}{c}{ Wasting } & \multicolumn{2}{c}{ Underweight } \\
& $N$ & $\%$ & $N$ & $\%$ & $N$ & $\%$ \\
\hline Sex & & & & & & \\
$\quad$ Male & & & & & & \\
$\quad$ Severe & 27 & 10.7 & 12 & 7.1 & 10 & 6 \\
$\quad$ Moderate & 29 & 17.3 & 13 & 7.7 & 25 & 14.9 \\
Female & & & & & & \\
$\quad$ Severe & 9 & 5.2 & 3 & 1.7 & 1 & 0.6 \\
$\quad$ Moderate & 29 & 16.7 & 10 & 5.7 & 13 & 7.5 \\
\hline
\end{tabular}

Maternal educational status, paternal educational status, monthly income, diarrhea $(\mathrm{AOR}=9.452$, 95\% CI: 4.34220.576), acute respiratory tract infection (AOR $=6.003,95 \%$ CI: 2.757-13.074), preterm (AOR $=3.942$, 95\% CI: $1.121-$ 13.85), and absence of antenatal follow-up ( $\mathrm{AOR}=4.45,95 \%$ CI: 1.41-14.06) were factors associated with wasting. 
TABLE 4: Nutritional status of children by age.

\begin{tabular}{lccc}
\hline \multirow{2}{*}{ Age in months } & $\begin{array}{c}\text { Stunting } \\
N(\%)\end{array}$ & $\begin{array}{c}\text { Wasting } \\
N(\%)\end{array}$ & $\begin{array}{c}\text { Underweight } \\
N(\%)\end{array}$ \\
\hline$<12$ & $9(15.3)$ & $9(15.3)$ & $7(11.9)$ \\
$12-23$ & $24(32.9)$ & $7(9.6)$ & $8(11)$ \\
$24-35$ & $16(20.5)$ & $8(10.3)$ & $14(17.9)$ \\
$36-47$ & $18(29.5)$ & $7(11.5)$ & $13(21.3)$ \\
$48-58$ & $18(25.4)$ & $7(9.9)$ & $7(9.9)$ \\
\hline
\end{tabular}

Male sex $(\mathrm{AOR}=2.91,95 \% \mathrm{CI}: 1.430-5.915)$, paternal educational status, preterm baby $(\mathrm{AOR}=3.71,95 \% \mathrm{CI}$ : $1.05-$ 13.11), antenatal follow-up $(\mathrm{AOR}=10.50$, 95\% CI: $3.24-$ 33.99), diarrheal disease ( $\mathrm{AOR}=3.306,95 \% \mathrm{CI}: 1.421-6.79)$, and acute respiratory tract infection $(\mathrm{AOR}=2.42,95 \% \mathrm{CI}$ : 1.09-5.38) were factors which affected underweight children (Table 5).

\section{Discussion}

The overall undernutrition was $35.5 \%$. The levels of stunting, wasting, and underweight were $24.9 \%, 11.1 \%$, and $14.3 \%$, respectively. The prevalence reported in this study is lower than the 2011 EDHS report, of which $44 \%$ was stunting and $29 \%$ was underweight [15].

In this study, prevalence of stunting was $24.9 \%$. This is congruent with previous reports in Gumbrit [16], was 24\%, China [19], was 20\%, and Pakistan [20], was $21 \%$. However, the finding of this study was lower than the 2013 UNICEF report in which the prevalence was $40 \%$ and $39 \%$ in SubSaharan Africa and in South Asia, respectively [3]. This is also lower than studies reported in Khartoum, Sudan (51\%) [21], Botswana (38.7\%) [22], India (49.36\%) [23], Vietnam (36.3\%) [24], Bule Hora, Ethiopia (47.6\%) [25], Somalia region, Ethiopia (34.4\%) [26], and North Wollo, Ethiopia $(44.5 \%)$ [27]. These variations might be due to the policy direction from the government to reduce mortality rates below five years of age by two-thirds of 1990's mortality. The other discrepancy might be due to small sample size compared to the other studies. However, the prevalence of stunting in this study is higher than other studies reported in Nigeria [28], was $12.4 \%$, South Africa [29], was $18 \%$, and Nigeria [30], was $12.5 \%$. These might be due to deference in maternal educational status and economic development.

In this study, prevalence of wasting was $11.1 \%$. This is comparable with studies reported in Nigeria [28], was $9.5 \%$, Vietnam [24], was 10.2\%, Nigeria [30], was $8.5 \%$, and eastern rural Ethiopia [31], was 7.4\%, and the 2011 EDHS report [15], in which it was $10 \%$.

On the other hand, the prevalence of wasting is markedly lower than the previous studies in $28.52 \%$ in India [23]. However, this was higher than studies in Rwanda [32], in which it was $3.1 \%$. The possible explanation could be variation in sample size and study period. It might be also due to difference in socioeconomics and feeding habit.

Prevalence of underweight of this study was $14.3 \%$. This is lower than other studies reported in Vietnam, 27.7\% [24],
Kenya, 26.5\% [33], urban Union Council (UC) of Abbottabad District, $21 \%$ [20], and Nigeria, $14.8 \%$ [30]. However, this was higher than a report in Nigeria [28] and Ruanda [32], in which it was $2.5 \%$ and $8.5 \%$, respectively. These may be varying according to the geographical location and the study population and health policy difference between the two countries.

This study revealed that $7.9 \%, 4.4 \%$, and $3.2 \%$ had severe stunting, wasting, and underweight, respectively. These are congruent with the 2011 EDHS report in which $21 \%$ had severe stunting, $3 \%$ had severe wasting, and $9 \%$ were severely underweight [15].

This study revealed that male sex, parents' educational status, preterm babies, household monthly income, diarrhea, and respiratory tract infection in the last one month and those who had no antenatal follow-up were independently associated with outcome variables. Other comparable reports in rural China [19] and in Vietnam [24] indicated that LBW, multiparity, preterm birth, maternal education, and low household income were strongly associated with outcome variables. In another study in Somalia region, Ethiopia [26], age of the child, child sex, mothers' education, monthly income, and acute airway infections were factors associated with malnutrition. Another report in Butajira, Ethiopia, showed that male sex, low birth weight, poor maternal nutritional status, and rural residence were factors affecting infants' nutritional status [34]. Moreover, a report in North Wollo, Ethiopia [27], depicted that child age and sex were factors associated with outcome variables.

This study indicated that maternal educational status was independently associated with outcome variables. However, a study reported by Edris [16] showed that maternal education status had no significant association with nutritional status of the children. This could be attributed to the fact that the overwhelming majority of the mothers were illiterate and sample size was not adequate to detect differences [16].

A report of this study revealed that diarrhea and acute respiratory tract infections (ARTI) episodes in the last one month were important determinants of under nutrition. This concurred with findings in Nepal [35] which showed that diarrhea and ARTI were factors that contributed to children having malnutrition.

Although this study used standardized measurement tools and large sample size and included well-trained and professional nurses for collection of data which improved the quality of data, this study was limited to use other parameters of the nutritional assessment such as biochemical test and diversity dietary assessment.

6.1. Conclusion/Recommendation. Undernutrition was high among children below five years of age in Bure town. Although stunting and underweight were decreased as compared to 2011 EDHS report, the overall undernutrition was high. Males were more affected with undernutrition than females. Sex of the child, maternal educational status, low household income, preterm babies, lack of antenatal followup, diarrheal disease, and respiratory infections were factors that affected child's nutritional status. 


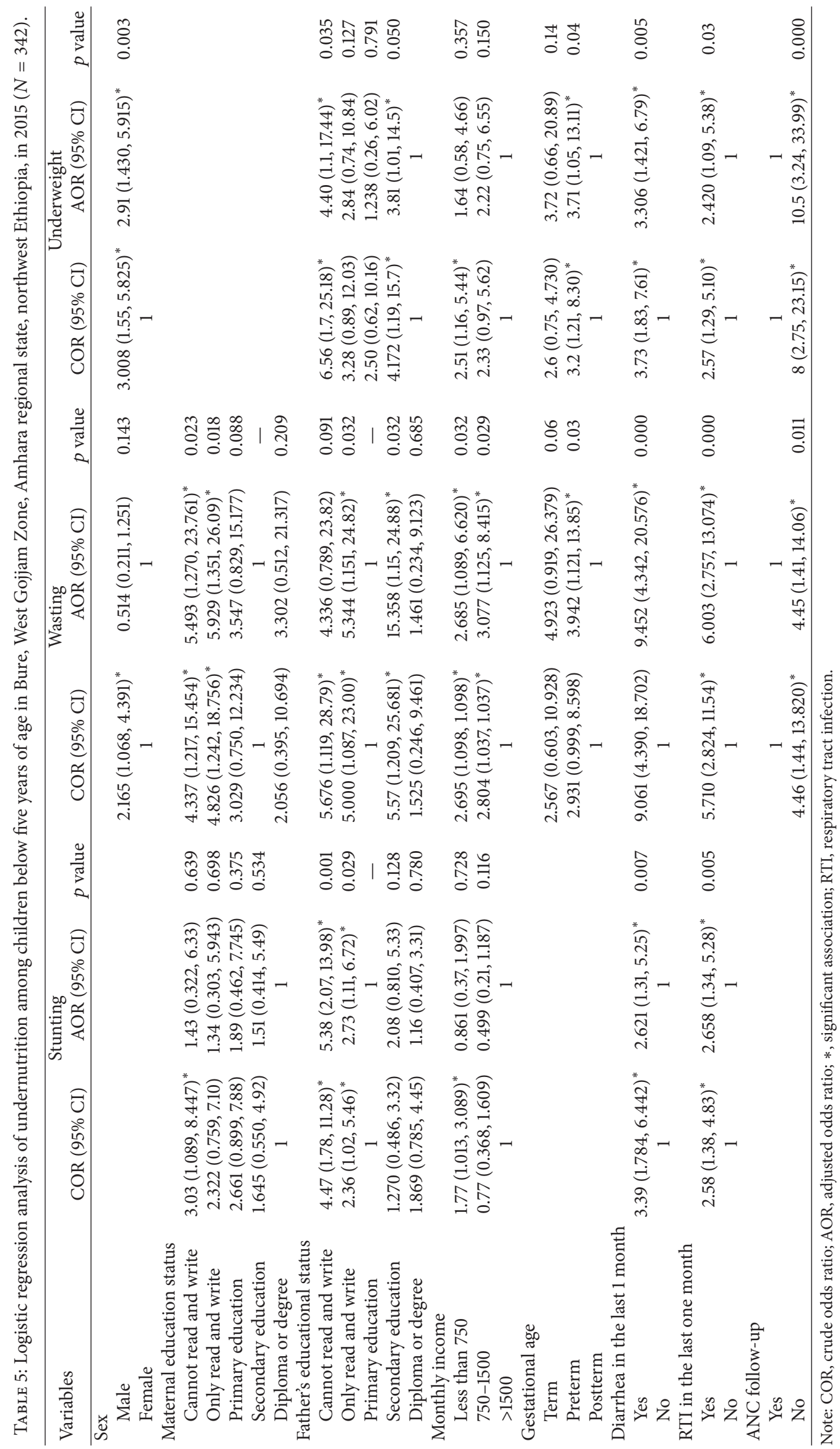


The government should be taking community-based interventions by giving priority to the poor households. Multisectorial partnership and networking are important for health promotion and minimizing child's food insecurity. Regional health bureau, zonal health department, and Woreda Health Office should be strengthening the health extension program to improve and provide necessary education on nutritional program, environmental sanitation, hygienic practice, breast feeding, and weaning practices.

Longitudinal and qualitative research shall be done on quantity and quality of nutrients and on the feeding habits of the community.

\section{Competing Interests}

The authors declare that there are no competing interests regarding the publication of this paper.

\section{Authors' Contributions}

All authors equally participated starting from conception to paper writing. Desalegne Amare, Ayenew Negesse, Baye Tsegaye, Birtukan Assefa, and Birehanu Ayenie participated in proposal writing, data collection, entry, analysis, and interpretation, and paper writing.

\section{Acknowledgments}

The authors gratefully thank Debre Markos University for technical and financial support. Their deepest gratitude goes to the data collectors and supervisors. Finally, they would like to thank the zonal health department and Woreda Health Department of West Gojjam.

\section{References}

[1] A. Sandoval-Priego, H. Reyes-Morales, and E. Orrico-Torres, "Family strategies of life associated with malnutrition in children less than 2 years of age," Salud Pública de México, vol. 44, pp. 41-49, 2002.

[2] S. A. Ohnson, Challenges in Health and Development: From Global to Community Perspectives, Springer Science \& Business Media, 2010.

[3] UNICEF, Improving Child Nutrition: The Achievable Imperative for Global Progress, United Nations Children's Fund, 2013.

[4] M. De Onis, D. Brown, M. Blossner, and E. Borghi, Levels and Trends in Child Malnutrition. UNICEF-WHO-The World Bank Joint Child Malnutrition Estimates, UNICEF, New York, NY, USA, 2012.

[5] C. K. Lutter and J. A. Rivera, "Nutritional status of infants and young children and characteristics of their diets," The Journal of Nutrition, vol. 133, no. 9, pp. 2941S-2949S, 2003.

[6] B. Holaday, S. David, and M. L. Lobo, "Childhood diarrhea and malnutrition in Pakistan, part I: incidence and prevalence," Journal of Pediatric Nursing, vol. 10, no. 2, pp. 131-137, 1995.

[7] G. Pechlaner and G. Otero, "The neoliberal food regime: neoregulation and the new division of labor in North America," Rural Sociology, vol. 75, no. 2, pp. 179-208, 2010.
[8] R. E. Black, L. H. Allen, Z. A. Bhutta et al., "Maternal and child undernutrition: global and regional exposures and health consequences," The Lancet, vol. 371, no. 9608, pp. 243-260, 2008.

[9] C. G. Victora, L. Adair, C. Fall et al., "Maternal and child undernutrition: consequences for adult health and human capital," The Lancet, vol. 371, no. 9609, pp. 340-357, 2008.

[10] J. Currie and D. Almond, "Human capital development before age five," Handbook of Labor Economics, vol. 4, pp. 1315-1486, 2011.

[11] R. Martorell, P. Melgar, J. A. Maluccio, A. D. Stein, and J. A. Rivera, "The nutrition intervention improved adult human capital and economic productivity," The Journal of Nutrition, vol. 140, no. 2, pp. 411-414, 2010.

[12] K. G. Dewey and K. Begum, "Long-term consequences of stunting in early life," Maternal and Child Nutrition, vol. 7, no. 3, pp. 5-18, 2011.

[13] S. Grantham-McGregor, Y. B. Cheung, S. Cueto, P. Glewwe, L. Richter, and B. Strupp, "Developmental potential in the first 5 years for children in developing countries," The Lancet, vol. 369, no. 9555, pp. 60-70, 2007.

[14] R. Martorell, B. L. Horta, L. S. Adair et al., "Weight gain in the first two years of life is an important predictor of schooling outcomes in pooled analyses from five birth cohorts from lowand middle-income countries," The Journal of Nutrition, vol. 140, no. 2, pp. 348-354, 2010.

[15] Ethiopia Demographic and Health Survey 2011, Central Statistical Agency of Ethiopia, Addis Ababa, Ethiopia; ORC Macro, Calverton, Md, USA, 2012.

[16] M. Edris, "Assessment of nutritional status of preschool children of Gumbrit, North West Ethiopia," Ethiopian Journal of Health Development, vol. 21, no. 2, pp. 125-129, 2007.

[17] World Health Organization, Training Course on Child Growth Assessment, WHO, Geneva, Switzerland, 2008.

[18] WHO, Nutrition Landscape Information System (NLIS) Country Profile Indicators: Interpretation Guide, WHO, 2010.

[19] J. Zhang, J. Shi, J. H. Himes et al., "Undernutrition status of children under 5 years in Chinese rural areas-data from the National Rural Children Growth Standard Survey, 2006," Asia Pacific Journal of Clinical Nutrition, vol. 20, no. 4, pp. 584-592, 2011.

[20] S. L. Hassam, U. R. Mahmood, S. L. Fahd, W. Salim, and J. Huma, "Assessment of nutritional status of 1-5 year old children in an urban union council of abbottabad," Journal Ayub Medical College Abbottabad, vol. 22, no. 3, pp. 125-126, 2010.

[21] A. Mahgoub and A. Alshiek, "The impact of feeding practices on prevalence of under nutrition among 6-59 months aged children in Khartoum," Sudanese Journal of Public Health, vol. 5, no. 3, pp. 152-157, 2010.

[22] S. E. Mahgoub, M. Nnyepi, and T. Bandeke, "Factors affecting prevalence of malnutrition among children under three years of age in Botswana," African Journal of Food Agriculture Nutrition and Development, vol. 6, no. 1, 2006.

[23] H. T. Pandve and S. A. Singru, "Various anthropometric methods of assessment of nutritional status in under five children," Indian Medical Gazette, vol. 9, no. 1, pp. 349-351, 2012.

[24] N. N. Hien and N. N. Hoa, "Nutritional status and determinants of malnutrition in children under three years of age in Nghean, Vietnam," Pakistan Journal of Nutrition, vol. 8, no. 7, pp. 958964, 2009.

[25] M. Asfaw, M. Wondaferash, M. Taha, and L. Dube, "Prevalence of undernutrition and associated factors among children aged 
between six to fifty nine months in Bule Hora district, South Ethiopia," BMC Public Health, vol. 15, article 41, 2015.

[26] S. Demissie, "Magnitude and factors associated with malnutrition in children 6-59 months of age in pastoral community of Dollo Ado District, Somali Region, Ethiopia," Science Journal of Public Health, vol. 1, no. 4, p. 175, 2013.

[27] E. Wollo, "Risk factors for child under-nutrition with a human rights edge in rural villages of North Wollo, Ethiopia," East African Medical Journal, vol. 82, no. 12, pp. 625-630, 2005.

[28] M. Ozor, O. Iyamu, and U. Osifo, "Prevalence of under nutrition among under five year children in Ekpoma, Edo-Nigeria," International Journal of Community Research, vol. 3, pp. 34-38, 2014.

[29] E. W. Kimani-Murage, S. A. Norris, J. M. Pettifor et al., "Nutritional status and HIV in rural South African children," BMC Pediatrics, vol. 11, article 23, 2011.

[30] J. A. Quadri and M. A. Ojure, "Assessment of nutritional status of under-five children in Akure South local government, Ondo state, Nigeria," International Journal of Recent Research and Applied Studies, vol. 14, no. 3, 2013.

[31] G. Egata, Y. Berhane, and A. Worku, "Seasonal variation in the prevalence of acute undernutrition among children under five years of age in east rural Ethiopia: A Longitudinal Study," BMC Public Health, vol. 13, no. 1, article 864, 2013.

[32] M. Niyibituronsa, F. Kyallo, C. Mugo, and S. Gaidashova, "Improving the nutritional status of malnourished children using soybean products in Rwanda," African Journal of Food, Agriculture, Nutrition and Development, vol. 14, pp. 9136-9153, 2014.

[33] F. N. Kariuki, J. M. Monari, M. M. Kibui et al., "Prevalence and risk factors of malnutrition," Journal of the National Institute of Public Health, vol. 51, no. 1, 2002.

[34] G. Medhin, C. Hanlon, M. Dewey et al., "Prevalence and predictors of undernutrition among infants aged six and twelve months in Butajira, Ethiopia: the P-MaMiE Birth cohort," BMC Public Health, vol. 10, article 27, 2010.

[35] T. R. Bhandari and M. Chhetri, "Nutritional status of under five year children and factors associated in Kapilvastu District, Nepal," Journal of Nutritional Health \& Food Science, vol. 1, no. 1, 2013. 


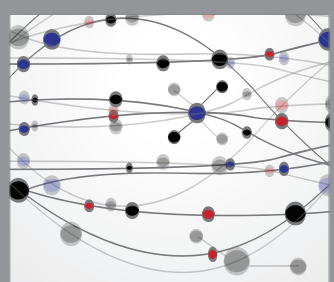

The Scientific World Journal
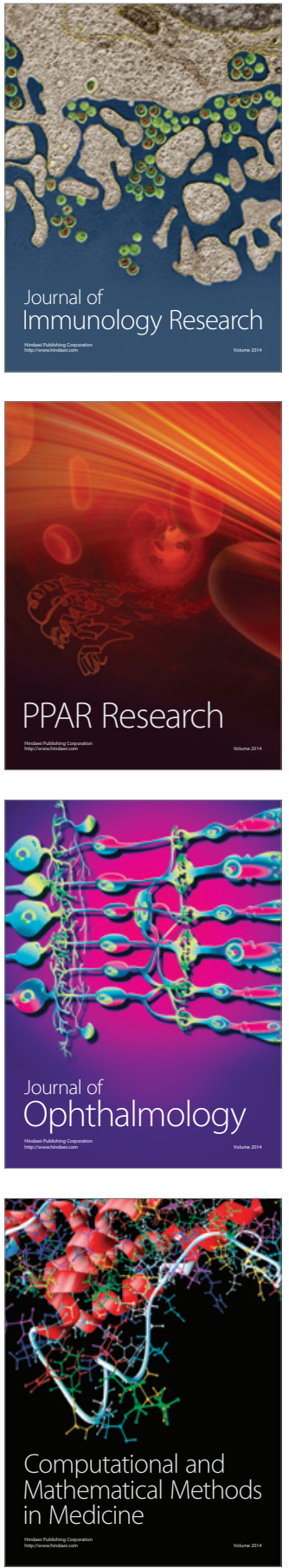

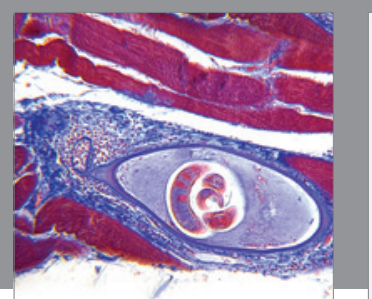

Gastroenterology Research and Practice

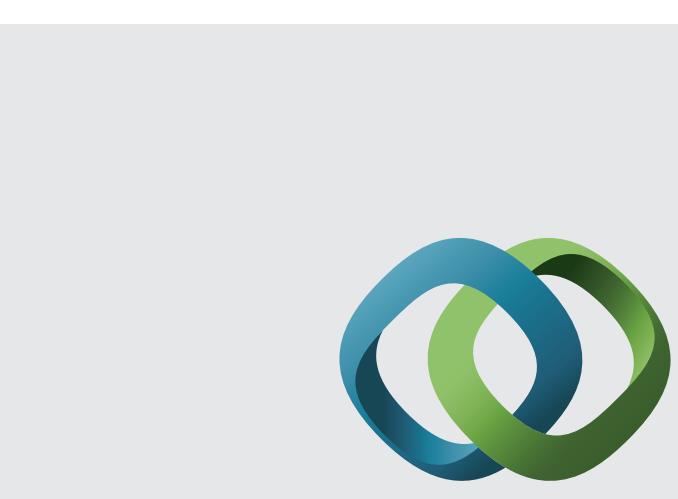

\section{Hindawi}

Submit your manuscripts at

http://www.hindawi.com
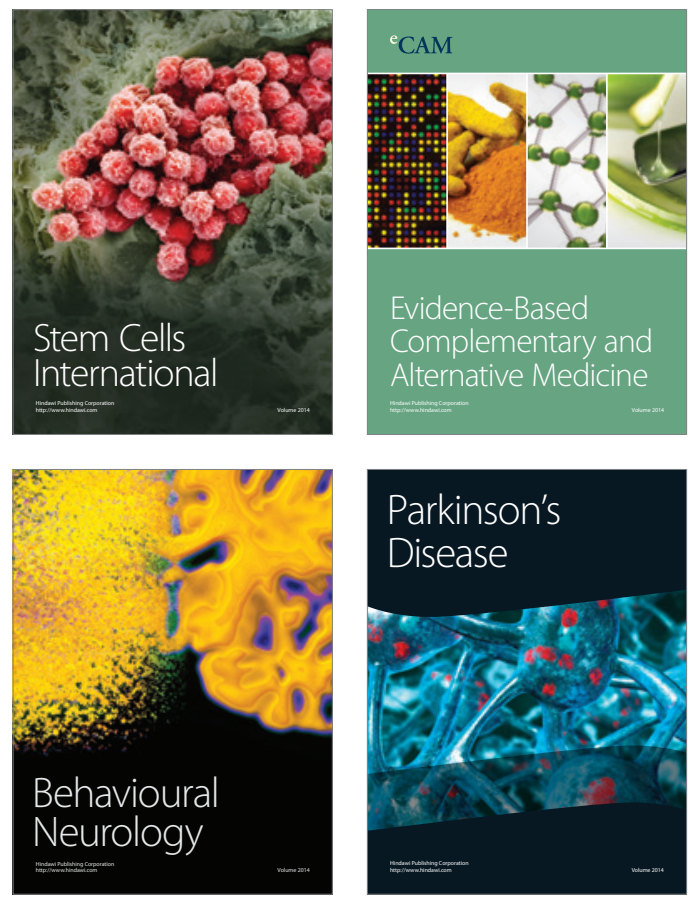
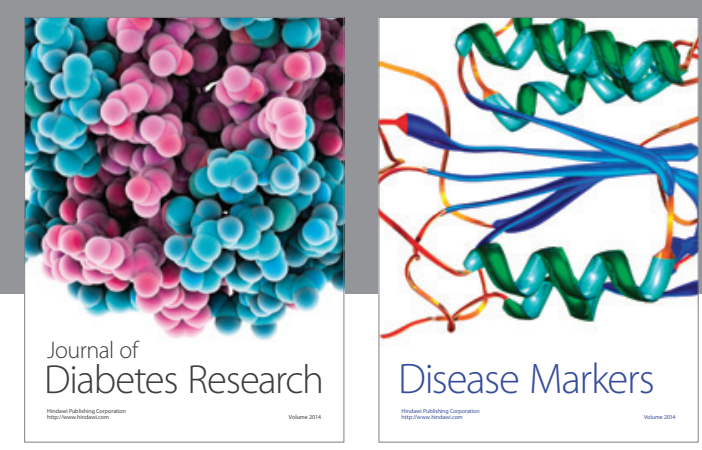

Disease Markers
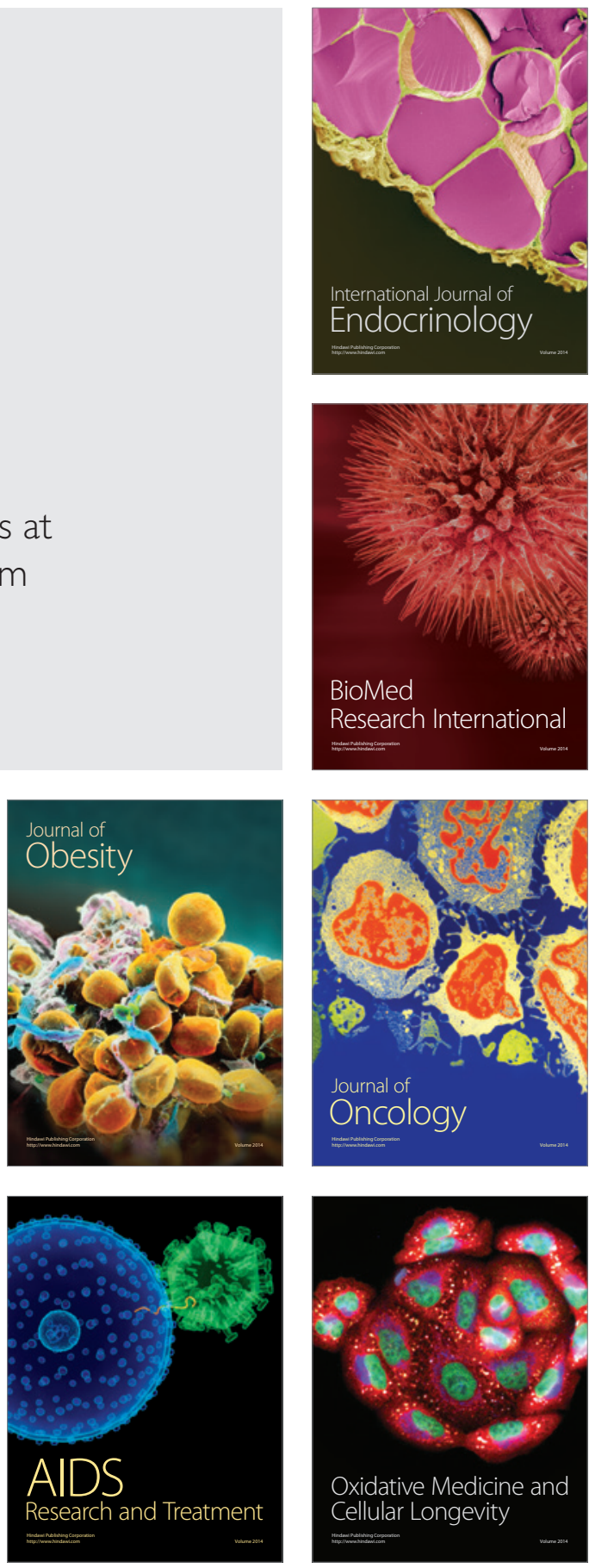